\title{
АНАЛИЗ ЭПИДЕМИОЛОГИЧЕСКИХ ПОКАЗАТЕЛЕЙ ГИПОФИЗАРНОГО НАНИЗМА В ДЕТСКОЙ ВОЗРАСТНОЙ ГРУППЕ ХМАО-ЮГРЫ
}

\author{
Я.В. Гирш, 3.А. Ахмедова \\ БУ ВО Ханты-Мансийского автономного округа «Сургутский государственный университет», \\ 2. Сургут
}

ВВЕДЕНИЕ: В настоящее время, благодаря программе «14 В3Н», все дети с гипофизарным нанизмом обеспечены заместительной терапией отечественным гормоном роста.

ЦЕЛЬ. Дать динамическую оценку эпидемиологических показателей в группе детей и подростков с гипофизарным нанизмом в ХМАО-Югре за период 2017-2021 гг.

МАТЕРИАЛ И МЕТОДЫ. Методом описательной статистики проведен анализ эпидемиологических показателей, характеризующих группу детей 0-17 лет с соматотропной недостаточностью (СТН) в ХМАО-Югре за последние 5 лет.

Предметом исследования являются статистические данные по гипофизарному нанизму (Государственный Федеральный регистр 14 В3Н и форма №12).

Объект исследования. Дети и подростки с СТН 0-17 лет, проживающих на территории ХМАО-Югры.

РЕЗУЛЬТАТЫ ИССЛЕДОВАНИЯ. ГрУППа ДетеЙ И ПодростКОВ С ГИПофИзарнЫм нанИзмом остается относительно стабильной на протяжении последних лет. На 01.01.2021 г. в ХМАО-Югре зарегистрировано 75 пациентов с СТН, в 2020 г. - 76, в 2019 г. - 70, в 2018 г. - 79, в 2017 г. — 77 пациентов. В сравнении с показателями распространенности по России (11,4 на 100 тыс. детского населения) и Уральскому Федеральному округу (УРФО) (9,9 на 100 тыс. д.н.) (01.01.19 г.), распространенность данной патологии в округе можно расценить, как высокую. Распространенность в 2017 г. составила: 15,8 на 100 тыс. детского населения, в 2018 г. - 18,7 на 100 тыс. д.н., в 2019 г. 17,1 на 100 тыс. д.н., в 2020 г. - 16,9 на 100 тыс. д.н., в 2021 г. - 17,0 на 100 тыс. детского населения. 2018 г. характеризовался самым высоким уровнем распространенности изучаемой патологии.

Заболеваемость в детской возрастной группе в ХМАО-Югре также расценивается, как высокая: в 2017 г. составила 2,7 на 100 тыс. детского населения, в 2018 г. — 3,3 на 100 тыс. д.н., в 2019 г. 3,8 на 100 тыс. д.н., в 2020 г. - 3,6 на 100 тыс. д.н., в 2021 г. - 3,7 на 100 тыс. детского населения.

Оценка гендерных различий показала, что в группе пациентов ХМАО-Югры традиционно преобладают мальчики: 70\% и 30 - мальчики и девочки, соответственно.

Следует отметить, что в среднем, диагностика гипофизарного нанизма осуществляется относительно поздно в детской возрастной группе, что связано, прежде всего, с поздней обращаемостью пациентов. Однако, требуется большая настороженность врачей первичного звена по своевременному выделению группы пациентов с низкими показателями роста. Традиционно, высокий уровень выявляемости СТН приходится на школьный возраст, на среднюю и старшую возрастные группы, в сравнении с дошкольным периодом. Впервые в 2020 г. количество детей выявленных с диагнозом соматотропной недостаточности в возрасте 7-11 лет превысило старшую возрастную группу.

Назначение заместительной терапии гормоном роста осуществляется по традиционным схемам, в среднем, из расчета 0,033 мг/кг/сут. Число детей, получающих стандартные дозы гормона роста в округе меньше, в сравнении с теми, которые получают терапию с превышением традиционных рекомендаций: 1: 1,3, что связано с высоким удельным весом пациентов старшего школьного возраста и их достаточно высоких показателей массы тела.

ВывОДы. Данные распространенности и заболеваемости гипофизарным нанизмом в ХМАО-Югре превышают средние показатели по Российской Федерации и УРФО. За последние 5 лет не группа пациентов с гипофизарным нанизмом остается относительно постоянной. Анализ эпидемиологических показателей позволяют прогнозировать и эффективно использовать средства, выделяемые для лечения данной пациентов. Требуется улучшение ранней диагностики гипофизарного нанизма среди детей дошкольного возраста, что позволит обеспечить лучший ростовой прогноз пациентов и улучшить социальную адаптацию детей. 